\title{
Distribuição Espacial dos Metadados Temporais e Qualidade dos Metadados Espaciais das Estações Hidrometeorológicas do Estado de Santa Catarina para Climatologia
}

\author{
Luiz Fernando de Novaes Vianna $^{1}$ (iD, Ângelo Mendes Massignan ${ }^{1}$ \\ ${ }^{1}$ Empresa de Pesquisa Agropecuária e Extensão Rural de Santa Catarina, \\ Centro de Informações de Recursos Ambientais e de Hidrometeorologia de Santa Catarina, \\ Florianópolis, SC, Brasil.
}

Recebido em 18 de Outubro de 2017 - Aceito em 10 de Maio de 2018

\begin{abstract}
Resumo
O objetivo deste trabalho foi avaliar a distribuição espacial dos metadados temporais (data de início e data fim) e a qualidade dos metadados espaciais (latitude, longitude e altitude) das estações hidrometeorológicas do estado de Santa Catarina, em relação às recomendações da Organização Mundial de Meteorologia - WMO para estudos climáticos. Foram avaliados os metadados das estações hidrometeorológicas, mantidas pela Empresa de Pesquisa Agropecuária e Extensão Rural de Santa Catarina - Epagri, até 30/06/2017. Os resultados demonstraram que o estado de Santa Catarina possui poucas estações com séries históricas superiores ao período mínimo de 30 anos, indicado pela WMO para realizar estudos climáticos. E que a distribuição espacial dessas estações não atende ao padrão de representatividade territorial estabelecido pela WMO. Apesar dos avanços no processo de gestão da rede de estações, o estado de Santa Catarina precisa se adequar a todas as recomendações da WMO para garantir a qualidade dos metadados temporais e espaciais das estações de monitoramento climático.
\end{abstract}

Palavras-chave: meteorologia, georreferenciamento, registro

\section{Spatial Distribution of Temporal Metadata and Spatial Metadata Quality of Santa Catarina State Weather Stations for Climatology}

\begin{abstract}
The objective of this paper was to evaluate the temporal (start date and end date) and spatial metadata (latitude, longitude and altitude) of the Santa Catarina state weather stations, based on the recommendations of the World Meteorological Organization - WMO for climate studies. Metadata of the weather stations maintained by the Empresa de Pesquisa Agropecuária e Extensão Rural de Santa Catarina - Epagri until 06/30/2017 were evaluated. The Santa Catarina state has few weather stations with historical series above the minimum period of 30 years, indicated by WMO to carry out climatic studies. The spatial distribution of weather stations are not in accordance with the pattern of territorial representation established by WMO. Despite advances in the weather stations network management process, the state of Santa Catarina needs to comply with all recommendations of WMO, to ensure the quality of the temporal and spatial metadata of climate monitoring stations.
\end{abstract}

Keywords: meteorology, georeferencing, register.

\section{Introdução}

O ponto de partida para estruturar uma base de dados climatológicos de superfície é a escolha dos sítios de monitoramento climático. Segundo a Organização Mundial de Meteorologia - WMO (2007) cada ponto de observação sinótica de superfície deve estar localizado em um sítio onde os dados meteorológicos obtidos representem, territorialmente, o comportamento atmosférico de regiões homogêneas entre $2.000 \mathrm{~km}^{2}$ e $10.000 \mathrm{~km}^{2}$, dependendo da variabilidade do relevo. Cada país possui normas específicas de construção e gestão das suas estações meteoro-

Autor de correspondência: Luiz Fernando de Novaes Vianna, vianna@epagri.sc.gov.br. 
lógicas, bem como normas específicas relacionadas à coleta, arquivamento e distribuição dos dados (Biossonade, 2002), porém a WMO recomenda a adoção de alguns processos e padrões para que os dados possam ser coletados de forma homogênea para uso em climatologia (WMO, 2007; WMO, 2008; WMO, 2015).

Garantir a homogeneidade dos dados climatológicos passa pelo conhecimento integral dos metadados espaciais e temporais de cada local de monitoramento. Esse conhecimento é representado pela posição geográfica e pelo registro das datas de início de operação, de cada manutenção executada e do fim da operação das estações. Assim tanto os metadados relacionados ao cadastro (código, posição geográfica e altitude) quanto os metadados gerenciais (responsáveis pela estação, datas de operação, instrumentação, etc.) devem estar sempre atualizados e disponíveis (Vianna et al., 2017).

A WMO determina que as coordenadas geográficas e a altitude de cada estação meteorológica sejam coletadas com referência ao Datum WGS 1984. As coordenadas geográficas devem ser obtidas e disponibilizadas com precisão de 0,001 graus decimais $(\sim 111,12 \mathrm{~m})$. Essas coordenadas devem referenciar o ponto onde as medições são realizadas e não podem ser substituídas por pontos representativos de localidades, vilas, bairros ou cidades que eventualmente dão nome à estação. A altitude da estação deve ser medida em metros acima do nível médio do mar, considerando a altura dos sensores acima do solo, baseando-se preferencialmente nos sensores de precipitação, temperatura e pressão (WMO, 2008).

Modificações nos sítios ou realocações são as maiores causas de quebra de homogeneidade nas séries de dados climatológicos. Além das mudanças de sítios, Vianna et al. (2017) identificaram problemas de arredondamento de casas decimais e de segundos nas coordenadas geográficas, que também ocasionam diferenças de posicionamento significativas. A WMO possui um guia específico (WMO, 2007b), no qual define 10 princípios básicos de monitoramento climático que devem ser seguidos quando a realocação de uma estação meteorológica é necessária, quando uma estação é substituída por outra próxima ou quando há troca de sensores. Nesses casos as estações devem operar simultaneamente por pelo menos um ano, mas preferencialmente por no mínimo dois anos, para determinar os efeitos das mudanças de local e/ou dos sensores. Cada estação (antiga e nova) deve possuir um código identificador único para auxiliar na gestão da estação e no armazenamento e disponibilização dos dados.

Trewin (2010) fez uma avançada revisão sobre o que denominou "fatores não climáticos" das inconsistências em séries históricas. Os mais significantes são a mudança de local das estações meteorológicas, as mudanças na paisagem do entorno e do próprio sítio onde se encontra a estação (ex. urbanização) e mudanças nas práticas de coleta dos dados (mudança de sensores, mudança de periodici- dade de coleta, etc.). Trewin (op. cit.) destaca ainda que tanto a escolha dos sítios quanto o objetivo do monitoramento podem divergir, como por exemplo no caso das estações meteorológicas instaladas nos aeroportos, que não têm como prioridade o monitoramento para fins climatológicos.

Para identificar possíveis influências dos fatores não climáticos nos dados climatológicos de Santa Catarina, o objetivo desse trabalho foi avaliar a distribuição espacial dos metadados temporais (período de operação) e a qualidade dos metadados espaciais (latitude, longitude e altitude) das estações hidrometeorológicas convencionais e telemétricas do estado de Santa Catarina, em relação às recomendações da WMO.

Especificamente buscou-se: (i) resgatar os metadados espaciais e temporais originais das estações; (ii) atualizar os metadados espaciais das estações para atender à precisão cartográfica mínima exigida pela WMO; (iii) analisar a distribuição espacial e temporal das estações; (iv) avaliar a diferença de posição horizontal (distância euclidiana) entre os pares de coordenadas originais e os pares de coordenadas atualizados das estações; e (v) avaliar a variação vertical (altitude) entre os metadados originais e os metadados atualizados das estações.

\section{Materiais e Métodos}

\subsection{Base de metadados}

Foram avaliados os metadados temporais (data de início e data fim) e a qualidade dos metadados espaciais (coordenadas geográficas em graus decimais e altitude em metros) das estações hidrometeorológicas do estado de Santa Catarina, mantidas pela Empresa de Pesquisa Agropecuária e Extensão Rural de Santa Catarina - Epagri.

Os metadados de 475 estações hidrometeorológicas foram obtidos em janeiro de 2017, atualizados e validados até 30/06/2017. Os metadados foram fornecidos em formato de texto (txt) tabular, com as estações organizadas por classe, tipo e status, seguindo o critério adotado pela Epagri (Blainski et al., 2012; Braga et al., 2014).

As estações foram classificadas em meteorológicas, hidrológicas ou maregráficas. As estações meteorológicas são aquelas projetadas para monitorar periodicamente uma ou mais variáveis físicas da baixa atmosfera, como temperatura do ar, umidade relativa do ar, precipitação pluviométrica, insolação, radiação solar, velocidade e direção do vento. As estações hidrológicas são destinadas à coleta sistemática de dados de precipitação pluviométrica e/ou nível dos rios. As estações maregráficas monitoram a variação de maré ao longo da costa de Santa Catarina.

Além das três classes, as estações foram organizadas em dois tipos, considerando o sistema de coleta, armazenamento e transmissão dos dados: convencionais e telemétricas. Os instrumentos das estações convencionais podem ser de leitura direta, como termômetro e pluviômetro, ou 
instrumentos com registro mecânico, como o actinógrafo, anemógrafo, termógrafo e higrógrafo. A coleta de dados a partir desses instrumentos é feita por um observador, que registra periodicamente os dados medidos. As estações telemétricas registram os dados automaticamente, em períodos prefixados e os armazenam em data loggers. Além disso, podem fazer a transmissão desses dados periodicamente para uma base de dados através de sistemas e protocolos específicos de transmissão.

O status das estações está relacionado ao seu período de operação e fornecimento de dados. Para as estações pertencentes à Epagri, cadastra-se a data de início de operação no momento de instalação de uma estação. A partir da data de início de operação, o status indica se a estação está transmitindo os dados regularmente (ativada) ou não (desativada). Uma estação é considerada ativada, quando os dados registrados pelos observadores (convencional) ou pelos instrumentos (telemétricas) estão sendo armazenados no banco de dados da Epagri. A partir do momento em que os dados deixam de ser registrados no banco, faz-se uma inspeção na estação. Caso ela necessite de ajustes, ela torna-se temporariamente desativada (manutenção), voltando a se tornar ativada após a retomada na obtenção dos dados. As estações desativadas são aquelas que deixaram de operar.

Para as estações pertencentes a outras instituições (ex. INMET, ANA) o status "ativada" significa que a estação está transmitindo os dados para o banco da Epagri. Quando os dados das estações de outras instituições deixam de ser armazenados no banco de dados da Epagri elas recebem o status de "desativada". Portanto, as datas de início e fim de "operação" das estações pertencentes às outras instituições podem não representar o período real de operação, mas apenas um período de fornecimento de dados.

\subsection{Verificação, validação e atualização das coordenadas e da altimetria}

Em 2008 foi feito um trabalho (não publicado) pelo setor de Geoprocessamento da Epagri, no qual realizou-se o levantamento das coordenadas de algumas estações hidrometeorológicas e criou-se um roteiro para coleta e cadastro dos metadados espaciais para as novas estações. Essa foi a primeira iniciativa para atualizar a posição geográfica das estações, porém a inexistência de documentos sobre esse procedimento dificultou a análise da qualidade das coordenadas ajustadas em 2008, em comparação às coordenadas originais. Os técnicos informaram que a atualização das coordenadas foi feita através da identificação das estações nas imagens do Google Earth. Aquelas que não foram identificadas nas imagens, tiveram as coordenadas coletadas em campo, com GPS de navegação. A atualização ocorreu apenas para as estações hidrometeorológicas que estavam ativadas na época ou para aquelas que, mesmo desativadas, foram identificadas nas imagens. Ainda de acordo com as informações fornecidas pelos técnicos, o objetivo do trabalho foi apenas atualizar as coordenadas, não havendo preocupação em avaliar a diferença existente em relação às coordenadas originais e tampouco atender ao padrão da WMO (WMO, 2007; WMO, 2008).

No presente trabalho, a verificação, validação e atualização das coordenadas das estações hidrometeorológicas foram feitas de forma a atender às especificações mínimas da WMO (WMO, 2007; WMO, 2008; WMO, 2015). A verificação abrangeu o processo de aquisição das coordenadas, considerando os ajustes realizados pela Epagri em 2008. Para as estações com data de início anteriores a $31 / 12 / 2007$ foram utilizadas as coordenadas armazenadas na base de metadados anterior à atualização realizada pelos técnicos da Epagri em 2008. Para as estações com data de início posterior a 01/01/2008, foram utilizadas as coordenadas existentes no banco de metadados até janeiro de 2017.

A validação foi feita através da verificação das coordenadas de cada estação em relação à sua real posição no terreno, considerando a precisão mínima de mapeamento de 0,001 graus, ou 111,12 m (WMO, 2007; WMO, 2008).

Para atualizar e validar as coordenadas das estações hidrometeorológicas foram utilizados, em ordem de prioridade: (i) o aerolevantamento do estado de Santa Catarina, com precisão e acurácia planialtimétrica de $1 \mathrm{~m}$ (SDS, 2012); e (ii) as imagens históricas de alta resolução disponíveis nos serviços de mapas do Google e da Esri, com precisão e acurácia variável (Esri et al., 2017). Para os dois métodos, a precisão foi superior àquela exigida pela $\mathrm{WMO}$ $(111,12 \mathrm{~m})$.

A atualização e validação das coordenadas foram feitas com auxílio da equipe de manutenção da rede de estações da Epagri e com o auxílio de técnicos e observadores municipais. Somente as coordenadas que tiveram a confirmação da sua real posição no terreno verificada pela equipe de manutenção foram consideradas validadas.

As estações hidrometeorológicas ativadas, com data de início anterior a 2012 e nitidamente identificáveis nas imagens, foram validadas e atualizadas com base no aerolevantamento (SDS, 2012). As estações hidrometeorológicas ativadas e com data de início posterior a 2012, foram validadas com base nas imagens históricas de alta resolução disponíveis nos serviços de mapas do Google e da Esri (Esri et al., 2017). As estações hidrometeorológicas desativadas que não foram nitidamente identificadas nem no aerolevantamento, nem nas imagens históricas, tiveram sua localização ajustada pela equipe técnica, com base em pontos de referência sobre a sua posição original. Nesse caso, os técnicos com conhecimento da localização original de cada estação identificaram a posição geográfica sobre as imagens de alta resolução, onde a estação operava. Mesmo não sendo possível visualizar essas estações nas imagens, os técnicos identificaram construções, rios, pontes, praças, 
ruas, esquinas e outras feições geográficas que atualmente cobrem a área onde a estação operou no passado.

Após a validação das coordenadas geográficas, a altimetria foi atualizada com base no modelo digital de terreno de Santa Catarina, com precisão altimétrica de $1 \mathrm{~m}$ (SDS, 2012). Os valores de altimetria foram extraídos para cada ponto de coordenada atualizada e validada, através da ferramenta Extract values to points do módulo Spatial Analyst do Sistema de Informações Geográficas (SIG) ArcGis 10.1.

\subsection{Análise dos metadados espaciais temporais das estações meteorológicas}

As análises da distribuição espacial dos dados temporais e da qualidade dos metadados espaciais foi feita apenas para as estações meteorológicas com coordenadas validadas. A justificativa está no fato das estações hidrológicas e maregráficas coletarem apenas dados de chuva, nível de rio e maré e na dificuldade que os autores e os técnicos tiveram em validar as coordenadas das estações hidrológicas (ver resultados).

A análise da distribuição espacial dos dados temporais das estações meteorológicas de Santa Catarina foi feita no SIG ArcGis 10.1 e no pacote estatístico R versão 3.3.3. Através dos metadados "data de início" e "data fim" das estações, foram gerados mapas e gráficos com a distribuição espacial e temporal das estações meteorológicas por tipo de estação e por década, entre os anos de 1911 e 2017.

As análises estatísticas da qualidade dos metadados espaciais das estações meteorológicas foram feitas com base na distância euclidiana e na diferença de altitude entre os pares de coordenadas originais e os pares de coordenadas atualizados, considerando o tipo e o status das estações. Os pares de coordenadas foram obtidos em graus decimais, Datum WGS-1984.

\subsection{Erro de posicionamento horizontal}

A distância euclidiana entre os pares de coordenadas foi calculada utilizando-se a biblioteca geosphere do R. Com base na precisão mínima de mapeamento de 0,001 graus, ou 111,12 m, sugerida pela WMO (WMO, 2007; WMO, 2008), as estações meteorológicas com distância euclidiana entre os pares de coordenadas originais e os pares de coordenadas atualizados e validados superior a $110 \mathrm{~m}$ foram consideradas estações com erro de posicionamento horizontal.

\subsection{Erro de posicionamento vertical}

A variação da altitude entre os pares de coordenadas foi calculada de modo a obter os valores absolutos da diferença entre a altitude original e a altitude do MDT (SDS,2012) em cada par de coordenadas atualizados e validados. A WMO não sugere uma precisão altimétrica mínima para posicionamento das estações, mas segundo a legislação brasileira (Brasil, 1985), a precisão planimétrica de 111,12 m sugerida pela WMO (WMO, 2007; WMO,
2008) corresponde a uma escala aproximada 1:370.000. Para cartas com escalas menores que a escala 1:250.00, o Instituto Brasileiro de Geografia e Estatística - IBGE utiliza a equidistância de $100 \mathrm{~m}$ entre as curvas de nível e o Padrão de Exatidão Cartográfica - PEC para cartas classe A (Brasil, 1985) adota o erro padrão médio correspondente a $1 / 3$ da equidistância entre as curvas de nível. Portanto, se a escala mínima exigida pela WMO é 1:370.00 e a equidistância entre as curvas de nível nessa escala deve ser de $100 \mathrm{~m}$, a precisão altimétrica mínima deve ser de $33 \mathrm{~m}$.

Além disso, segundo Massignan e Pandolfo (2006), em Santa Catarina a cada $100 \mathrm{~m}$ de altitude a temperatura varia, em valores absolutos, $0,6{ }^{\circ} \mathrm{C}$, o que indica uma variação de $0,2^{\circ} \mathrm{C}$ a cada $33 \mathrm{~m}$. O valor de $0,2^{\circ} \mathrm{C}$ corresponde à incerteza média relacionada às medições sistemáticas de temperatura global (Folland et al., 2001; Brohan et al., 2006).

Portanto, considerando a precisão planimétrica exigida pela WMO, as normas brasileiras de exatidão cartográfica, a correlação entre a variação de temperatura e a variação altimétrica em Santa Catarina e a incerteza média das medições sistemáticas de temperatura global, adotou-se como precisão altimétrica o valor de $30 \mathrm{~m}$ de altitude. As estações meteorológicas com diferença absoluta de altitude entre os pares de coordenadas originais e os pares de coordenadas atualizados e validados superior a $30 \mathrm{~m}$ foram consideradas estações com erro de posicionamento vertical.

\section{Resultados e Discussão}

\subsection{Resgate e atualização dos metadados espaciais das estações meteorológicas convencionais e telemétricas do estado de Santa Catarina}

Em 1916 o estado de Santa Catarina possuía 14 estações meteorológicas, sendo 13 custeadas pela união e uma gratuita (Ministério da Agricultura, 1917). Em janeiro de 2017 foram identificados, no banco da Epagri, os metadados espaciais e temporais de 614 estações, sendo 6 da Argentina, 41 do Paraná, 92 do Rio Grande do Sul e 475 de Santa Catarina. As estações foram classificadas em meteorológicas (350), hidrológicas (254) e marégrafos (10), sendo 457 telemétricas e 157 convencionais. Em relação ao status, 319 estavam desativadas e 295 permaneciam ativas. Os metadados indicaram a existência de dados para o período de 1911 a 2017.

Foram verificadas as coordenadas das 475 estações pertencentes ao estado de Santa Catarina (Tabela 1). Apenas as estações meteorológicas ativadas e os marégrafos tiveram $100 \%$ das coordenadas validadas. Nove estações meteorológicas convencionais desativadas não tiveram suas coordenadas verificadas pela dificuldade em localizálas. Eram estações antigas, instaladas entre 1923 e 1987 e desativadas há mais de 18 anos. Segundo os técnicos da Epagri, essas estações pertenciam a outras instituições e foram utilizadas como estações auxiliares. Sete estações 
Tabela 1 - Número total das estações, número das estações com as coordenadas validadas e porcentagem de estações com as coordenadas validadas por classe, tipo e status para Santa Catarina em 30/06/ 2017.

\begin{tabular}{lllccc}
\hline Classe & Tipo & Status & Número de estações & $\begin{array}{c}\text { Número de estações com as } \\
\text { coordenadas validadas }\end{array}$ & $\begin{array}{c}\% \text { de estações com as } \\
\text { coordenadas validadas }\end{array}$ \\
\hline Hidrológica & Telemétrica & Ativada & 67 & 58 & $86,5 \%$ \\
Hidrológica & Convencional & Desativada & 50 & 0 & 0 \\
Hidrológica & Telemétrica & Desativada & 83 & 23 & $27,7 \%$ \\
Marégrafos & Telemétrica & Ativada & 10 & 10 & $100 \%$ \\
Meteorológica & Convencional & Ativada & 14 & 14 & $100 \%$ \\
Meteorológica & Telemétrica & Ativada & 148 & 148 & $100 \%$ \\
Meteorológica & Convencional & Desativada & 48 & 39 & $81,2 \%$ \\
Meteorológica & Telemétrica & Desativada & 55 & 48 & $87,2 \%$ \\
Total & & 475 & 340 & $71,5 \%$ \\
\hline
\end{tabular}

meteorológicas telemétricas desativadas que não tiveram as coordenadas validadas também não faziam parte da rede de estações oficiais. Elas foram instaladas para atender às necessidades de um projeto de pesquisa e apresentaram problemas instrumentais e de comunicação. Foram instaladas entre 2006 e 2012 e desativadas entre 2011 e 2014.

Entre as estações hidrológicas, apenas 40,5\% tiveram as coordenadas validadas. Daquelas que já estavam desativadas, nenhuma das convencionais e somente $27,7 \%$ das telemétricas tiveram suas coordenadas validadas. Não há mais estações hidrológicas convencionais ativadas em Santa Catarina e das telemétricas em funcionamento foram validadas $86,5 \%$ das coordenadas.

Enquanto as estações meteorológicas possuem um padrão de construção (INMET, 2011), as estações hidrológicas devem seguir apenas sugestões de padronização (ANA, 2014). O padrão de construção do local de instalação das estações meteorológicas abrange uma área mínima de $252 \mathrm{~m}^{2}$, facilmente identificável em uma imagem de alta resolução (Fig. 1).

Já as estações hidrológicas podem ser alocadas em estruturas pré-existentes, como pontes, represas, barragens e usinas hidroelétricas ou em áreas abertas, além de necessitarem de uma área mínima de $6,25 \mathrm{~m}^{2}$ para construção. Com isso, a identificação das estações hidrológicas nas imagens foi mais difícil, mesmo para os técnicos responsáveis pela instalação e manutenção dessas estações.

Das 50 estações hidrológicas convencionais desativadas, 49 foram instaladas entre 01/11/1997 e 01/10/2009, sendo que a maioria (45) foi desativada entre 22/03/2010 e 02/07/2012, ou seja, durante a execução do aerolevantamento (SDS, 2012).

As estações hidrológicas convencionais desativadas já estão fora de operação há mais de 5 anos, e suas estruturas foram removidas antes do aerolevantamento da SDS (2012). Com isso, os técnicos não tiveram condições de validar as coordenadas existentes no banco de metadados, o que também ocorreu para as estações hidrológicas telemétricas desativadas.
As estações hidrológicas telemétricas ativadas pertencem à ANA e iniciaram sua operação entre maio de 2013 e outubro de 2016, após as imagens do aerolevantamento serem obtidas. Assim, os técnicos da Epagri recorreram ao uso das imagens de alta resolução disponíveis nos outros sistemas (Esri et al., 2017) e tiveram dificuldade para identificar e validar $13.5 \%$ dessas estações.

Por causa das dificuldades encontradas para validar as coordenadas das estações hidrológicas, as análises dos metadados espaciais concentraram-se nas 249 estações meteorológicas que tiveram as coordenadas validadas (Tabela 1). Apesar disso, reconhecemos a importância do resgate, da verificação e da validação das coordenadas das estações hidrológicas, uma vez que os dados gerados por essas estações também são de suma importância para trabalhos de climatologia, como os atlas climatológicos (INMET, 2009, EMBRAPA, 2011) ou para outros estudos (Pandolfo et al., 2002; Wrege et al., 2016; De Meli et al., 2016; Ávila et al. Back e Pasini, 2017). Porém o trabalho de recuperação histórica das coordenadas das estações hidrológicas exigirá um método diferente do que foi apresentado nesse artigo.

\subsection{Análise da distribuição espacial e temporal das estações meteorológicas convencionais e telemétricas do estado de Santa Catarina}

Na Fig. 2 observa-se a distribuição espacial, por década, das estações meteorológicas convencionais e telemétricas ativas em Santa Catarina. De acordo com a WMO (WMO, 2007) cada estação meteorológica deve representar uma área entre $2.000 \mathrm{~km}^{2}$ e $10.000 \mathrm{~km}^{2}$ de relevo homogêneo. Os metadados espaciais e temporais indicaram que apenas a partir da década de 90 o estado de Santa Catarina passou a contar com uma rede de estações meteorológicas com uma cobertura espacial mais representativa do território, porém ainda insuficiente para o padrão da WMO. Observou-se também, uma tendência de automatização e um maior adensamento da rede de estações meteorológicas a partir do ano 2000. Mas a distribuição espacial das esta- 


\section{Estações meteorológicas automáticas}
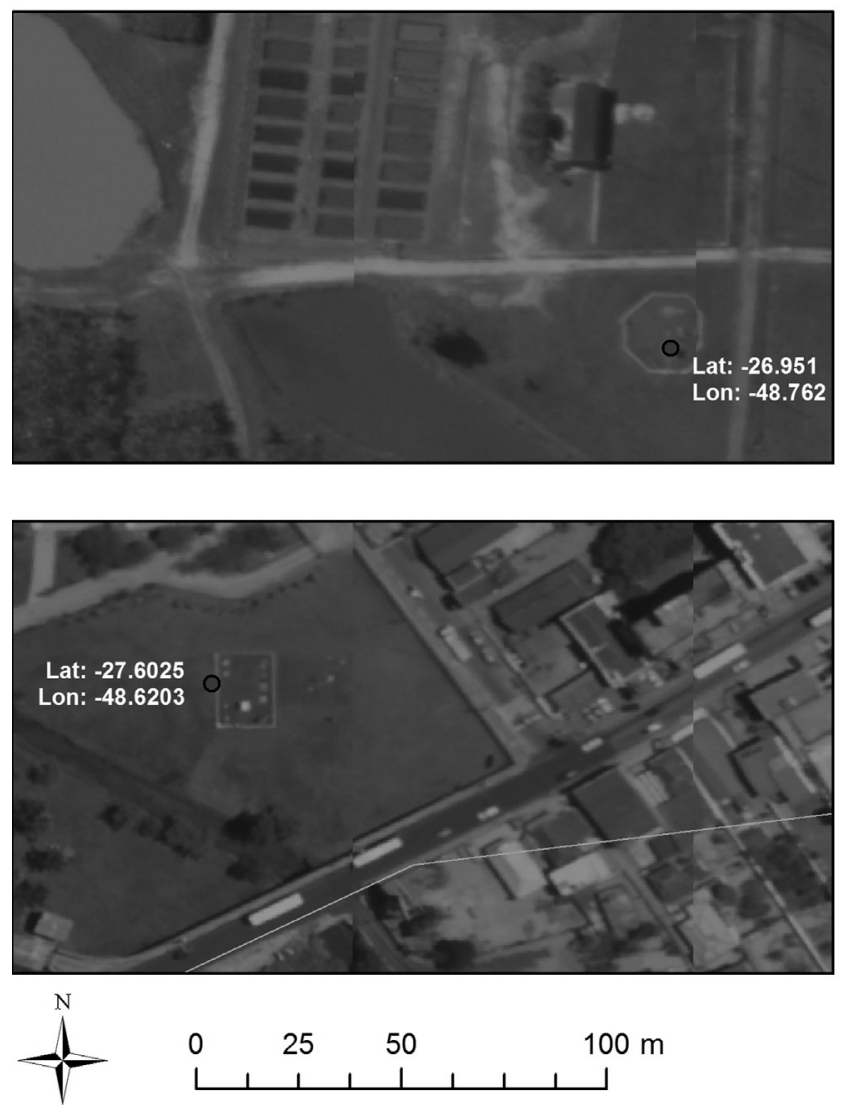

\section{Estações hidrológicas automáticas}
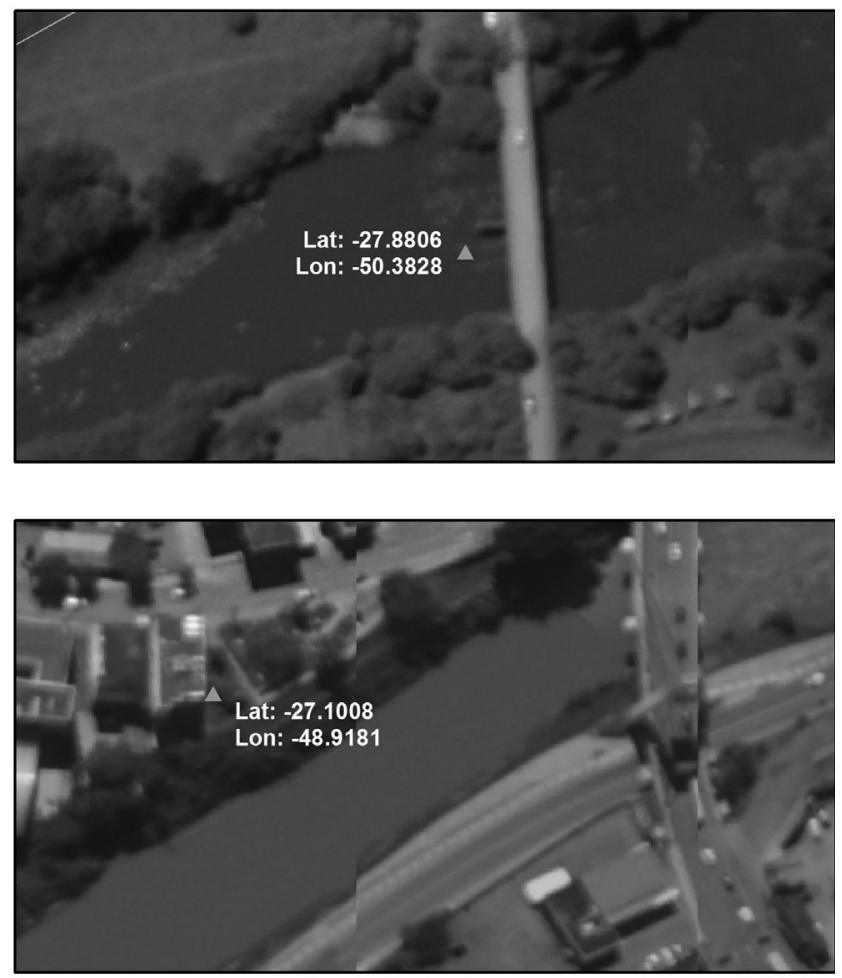

Figura 1 - Exemplo de padrões de locais para instalação das estações meteorológicas e hidrológicas telemétricas e sua capacidade de identificação visual nas imagens de alta resolução do aerolevantamento de Santa Catarina (SDS, 2012).

ções meteorológicas continua concentrada em determinadas regiões, não contribuindo para cobrir integralmente algumas falhas que ainda ocorrem na área do território de Santa Catarina.

Assim como foi observado espacialmente na Fig. 2, percebe-se um aumento significativo na quantidade de estações meteorológicas telemétricas instaladas em Santa Catarina a partir do ano 2000 (Fig. 3), porém com períodos de operação menores que os períodos de operação das estações convencionais. Algumas estações telemétricas foram instaladas para atender a projetos específicos de curta duração. Outras foram alocadas no mesmo sítio onde já operavam estações convencionais, mas não foram encontrados registros nos metadados que identificassem o objetivo da manutenção desses sítios. Há casos em que houve substituição das estações convencionais pelas telemétricas e há casos em que a aquisição de dados continua ocorrendo em duplicidade. Há também as estações telemétricas que foram instaladas em novos sítios.

As estações meteorológicas convencionais apresentaram, em média, tempo de operação próximo a 30 anos, enquanto para as telemétricas esse tempo foi inferior a 6 anos (Tabela 2).
Em 03/06/2017, Santa Catarina possuía 108 estações meteorológicas desativadas, sendo 48 convencionais e 60 telemétricas. O tempo médio de operação das estações meteorológicas desativadas convencionais foi de 29,1 anos, enquanto o tempo médio de operação das estações meteorológicas telemétricas desativadas foi de 5,7 anos. Ao analisarmos o tempo de operação médio (em anos) das estações meteorológicas a cada década (Fig. 4), percebemos uma tendência de queda gradual e contínua.

A tendência atual de redução no tempo de operação das estações meteorológicas, principalmente das estações telemétricas, desperta preocupação em relação aos estudos climáticos. O relatório especial do Painel Brasileiro de Mudanças Climáticas (PBMC, 2016) destacou Santa Catarina como um dos três estados brasileiros com maior ocorrência de desastres naturais associados às mudanças climáticas. Os impactos sociais dos desastres naturais em Santa Catarina também vêm sendo investigados (Siebert, 2017) e o governo estadual possui uma política pública específica para mudanças climáticas desde 2009 (Santa Catarina, 2009). Apesar disso, não há um programa governamental específico voltado à gestão da rede de monitoramento climático em Santa Catarina. E o desconhecimento a respeito da qualidade dos dados meteorológicos se deve, 

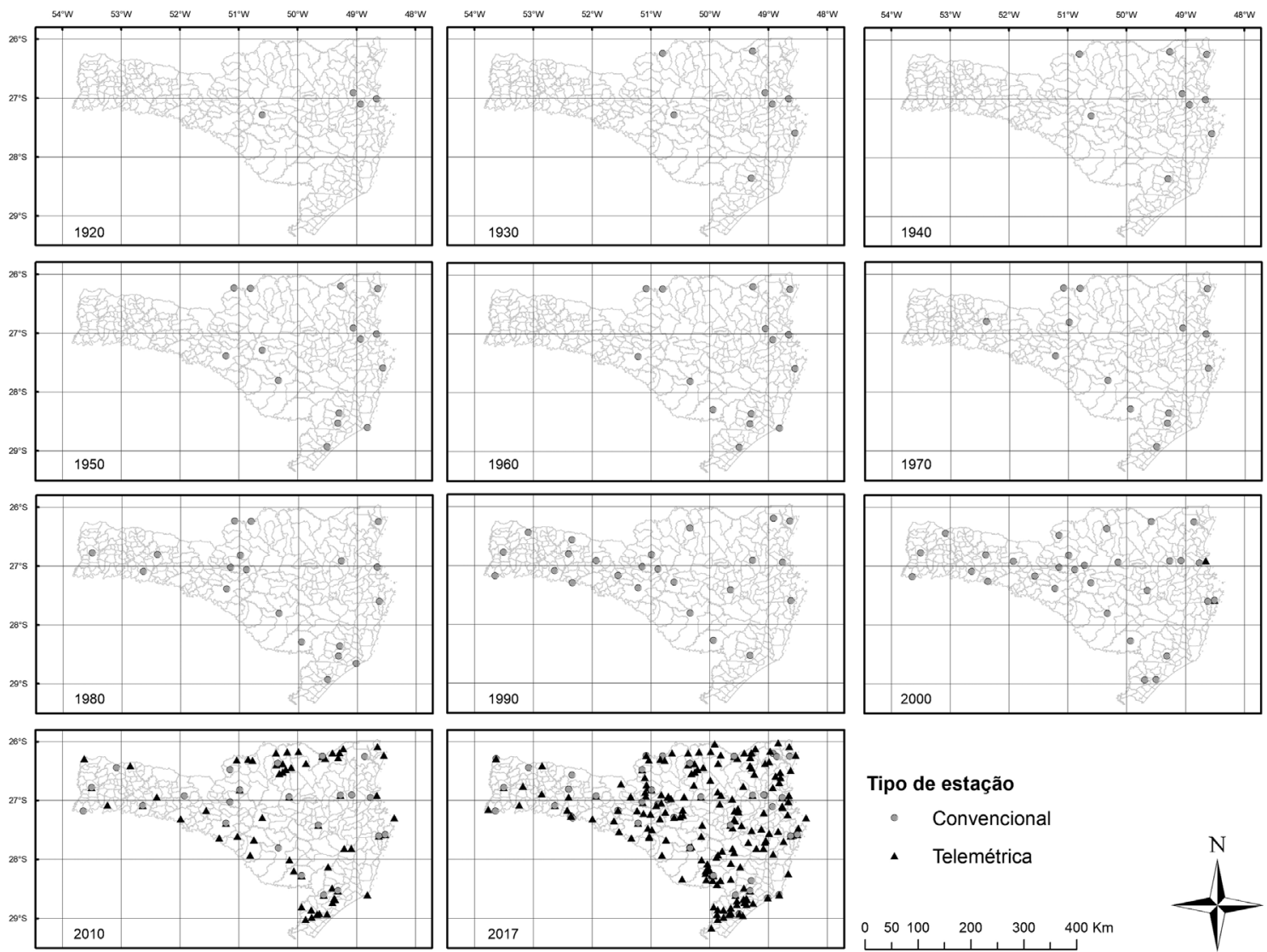

Figura 2 - Distribuição espacial das estações meteorológicas convencionais e telemétricas ativas por década no estado de Santa Catarina de 1911 a $30 / 06 / 2017$.

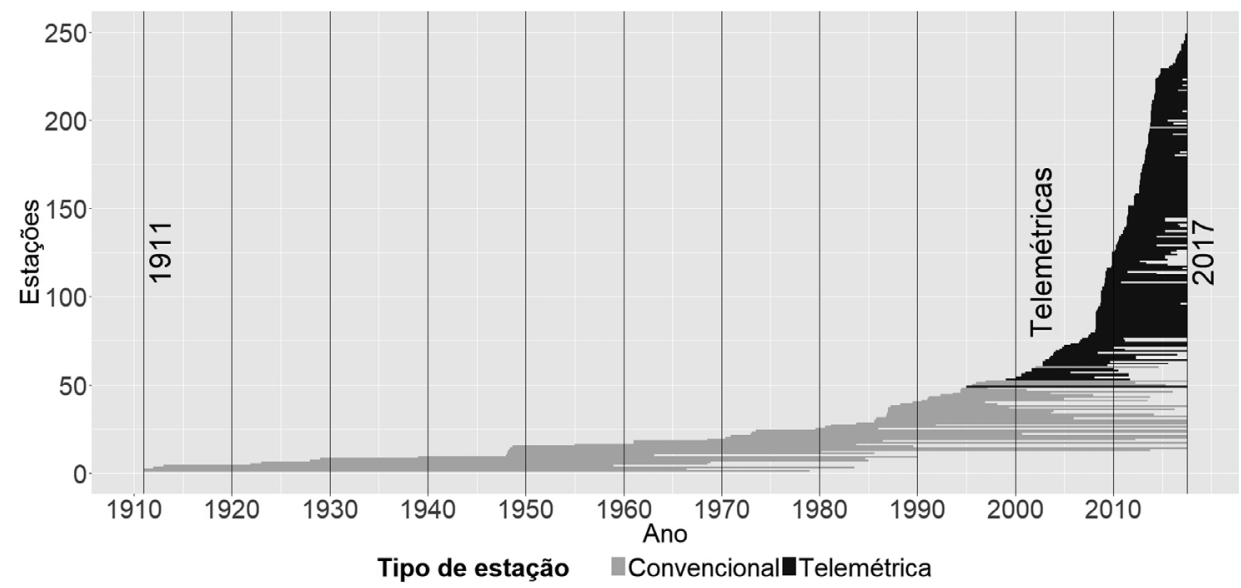

Figura 3 - Data de início e data fim da operação das estações meteorológicas convencionais e telemétricas no estado de Santa Catarina, para o período de 1911 até 30/06/2017.

em parte, à precariedade dos metadados cadastrais, seja em relação às instituições responsáveis pela sua manutenção, ou pela não aplicação dos protocolos existentes no que se refere ao cadastro espacial e temporal das estações (Vianna et al., 2017).

A análise mais antiga encontrada da distribuição espacial e temporal dos dados climatológicos em Santa
Catarina é da década de 50. A Fig. 5 foi extraída do Atlas Geográfico de Santa Catarina (DEGE, 1958) e representa a distribuição espacial de 19 estações meteorológicas convencionais, sendo 16 com dados de temperatura e precipitação e 3 apenas com dados de precipitação.

De acordo com os metadados atuais existem 26 estações meteorológicas convencionais com período de opera- 
Tabela 2 - Duração mínima, média, máxima e desvio padrão da duração entre a ativação e a desativação das estações meteorológicas, por status e tipo no estado de Santa Catarina de no período de 1911 a 30/06/2017.

\begin{tabular}{llcccc}
\hline Status & Tipo & Duração mín. & Duração méd. & Duração máx. & DP. da duração \\
\hline Ativada & Convencional & 3,8 & 37,7 & 69,1 & 15,8 \\
Ativada & Telemétrica & 0,2 & 5,6 & 22,5 & 3,3 \\
Desativada & Convencional & 2,7 & 29,1 & 71,6 & 19,1 \\
Desativada & Telemétrica & 1,7 & 5,7 & 12,8 & 2,9 \\
\hline
\end{tabular}

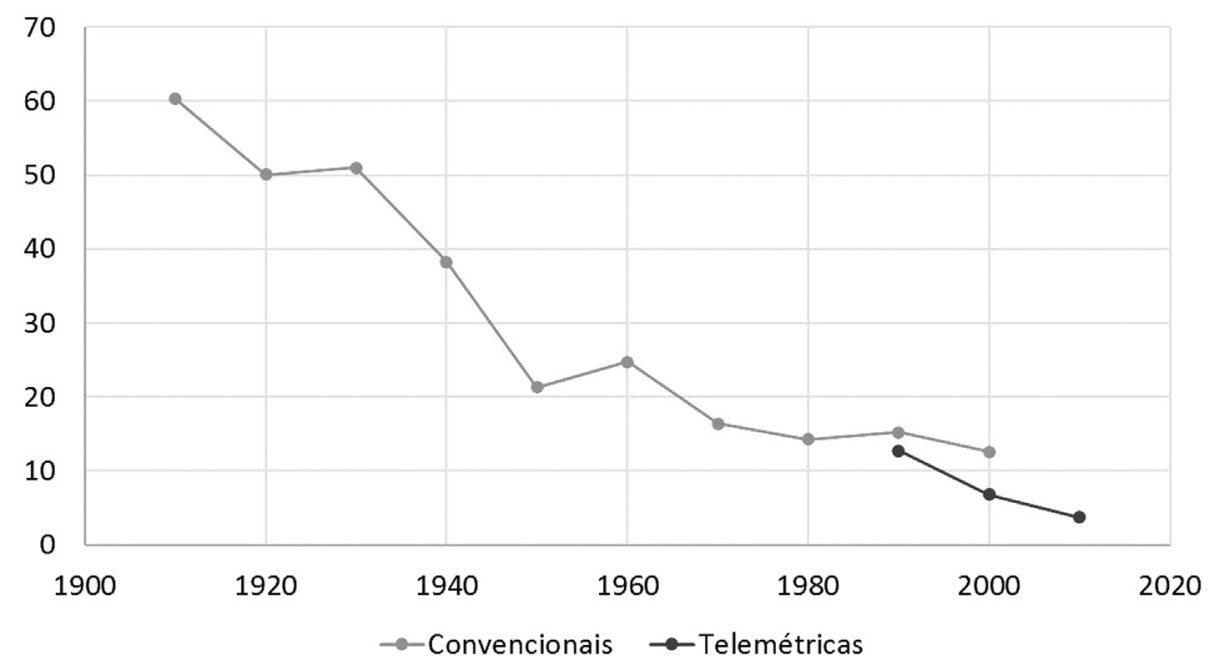

Figura 4 - Duração média (anos) das estações meteorológicas convencionais e telemétricas desativadas por década em Santa Catarina.

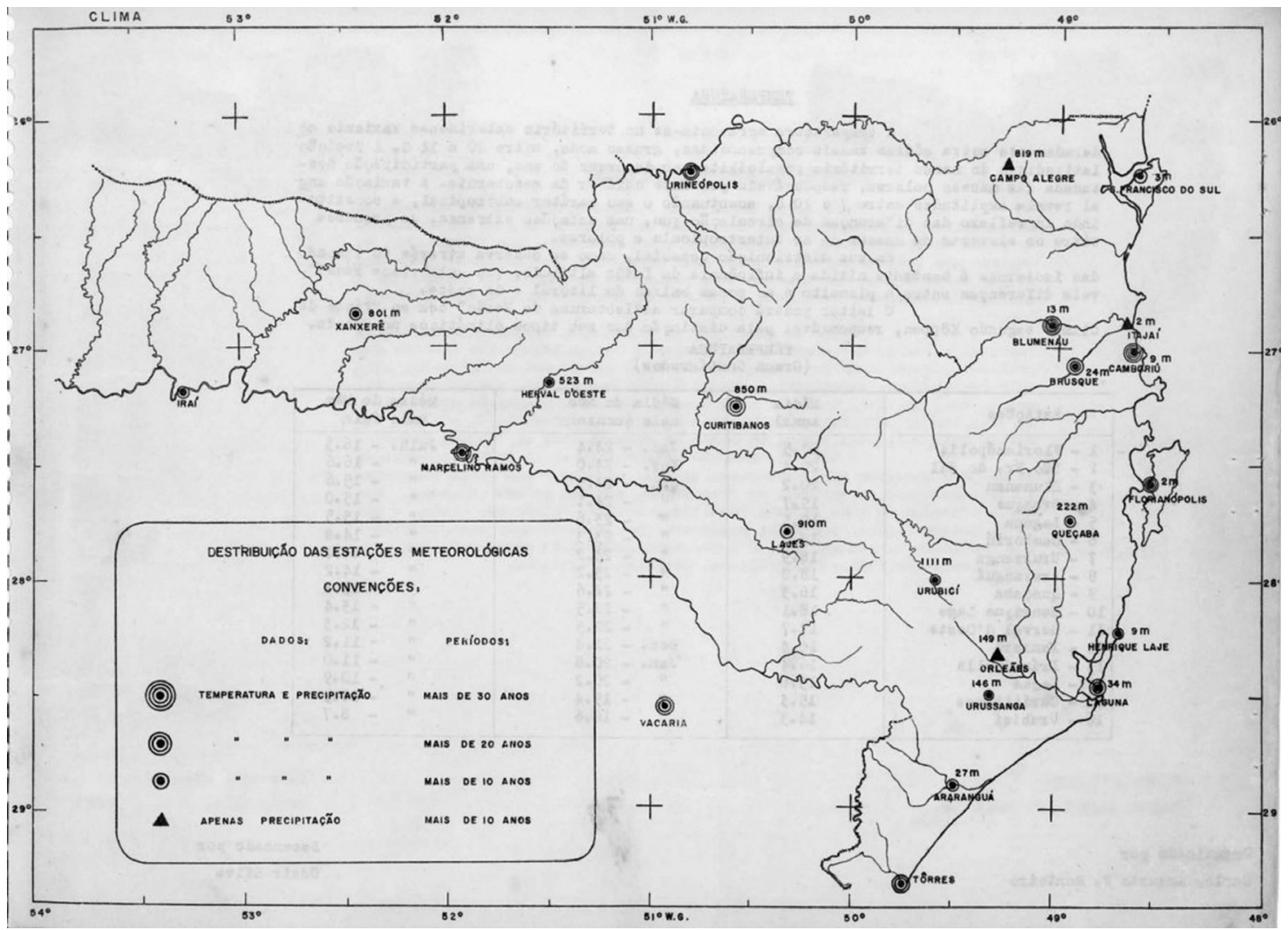

Figura 5 - Distribuição espacial e tempo de operação das estações meteorológicas convencionais em Santa Catarina na década de 50. Fonte: Atlas Geográfico de Santa Catarina (DEGE, 1958). 
ção superior a 30 anos (Fig. 6). Entre as estações meteorológicas telemétricas, $11 \%$ apresentaram menos de dois anos de operação, $42 \%$ entre 2 e 5 anos de operação, $41 \%$ entre 5 e 10 anos de operação, $6 \%$ entre 10 e 22,5 anos de operação.

Comparando as Figs. 5 e 6, percebemos que existem algumas inconsistências na distribuição espacial da duração da operação das estações meteorológicas convencionais. As estações de Queçaba e Henrique Lages, identificadas na Fig. 5, não aparecem nos metadados da Epagri (Fig. 6). Isso demonstra uma possível perda de dados históricos. A estação de Laguna por sua vez, não aparece na Fig. 6 porque suas coordenadas não foram validadas pelos técnicos da Epagri, mas seus metadados constam na base.

A estação de Xanxerê já operava há mais de 10 anos em 1958 (Fig. 5), mas nos metadados da Epagri constam dados apenas entre 1961 a 1986. Essa estação operou, pelo menos, a partir da década de 30 , pois seus dados foram utilizados pelo INMET no cálculo das normais climatológicas de 1931-1960 (INMET, 1979). As estações de Blumenau, Brusque e Camboriú possuem dados diários a partir de 1961, entretanto, as datas de início de atividade são 01/01/1911, 01/01/1911 e 01/01/1913, respectivamente. Em contraste, a estação de Campos Novos possui dados mensais no banco de dados desde 1913 e dados diários a partir de 1948, e a data inicial cadastrada nos metadados é 01/03/1948.

Essas inconsistências nas informações temporais se devem ao fato da Epagri não seguir um padrão de registro de datas em seus metadados. Há casos, como os das estações automáticas mais recentes, em que as datas de início e fim de operação correspondem ao período real de ativação e desativação. Mas existem estações, principalmente as de terceiros (ex. INMET, ANA), cujas datas de início e fim correspondem a períodos aleatórios, quando a Epagri recebeu os dados daquelas estações e armazenou em seu banco.

O tempo de operação das estações meteorológicas ao longo das décadas não é homogêneo nem espacial (Fig. 2) nem historicamente (Figs. 3 e 4). Segundo a WMO (WMO, 1989), para se calcular as normais climatológicas padrão, deve-se utilizar séries homogêneas para períodos de 30 anos de dados, com início em 1901. No Brasil, as observações meteorológicas sistemáticas tiveram início em 1910 (INMET, 1979). Por isso, as normais climatológicas oficiais do país só foram calculadas para os períodos 19311960 (INMET, op. cit.) e 1961-1990 (INMET, 2009).

Na Fig. 7 apresentamos a distribuição espacial das estações meteorológicas convencionais com os períodos de 30 anos de operação coincidentes com os períodos utilizados pela WMO para cálculo das normais climatológicas em Santa Catarina. Para o período 1931-1960 foram encon-

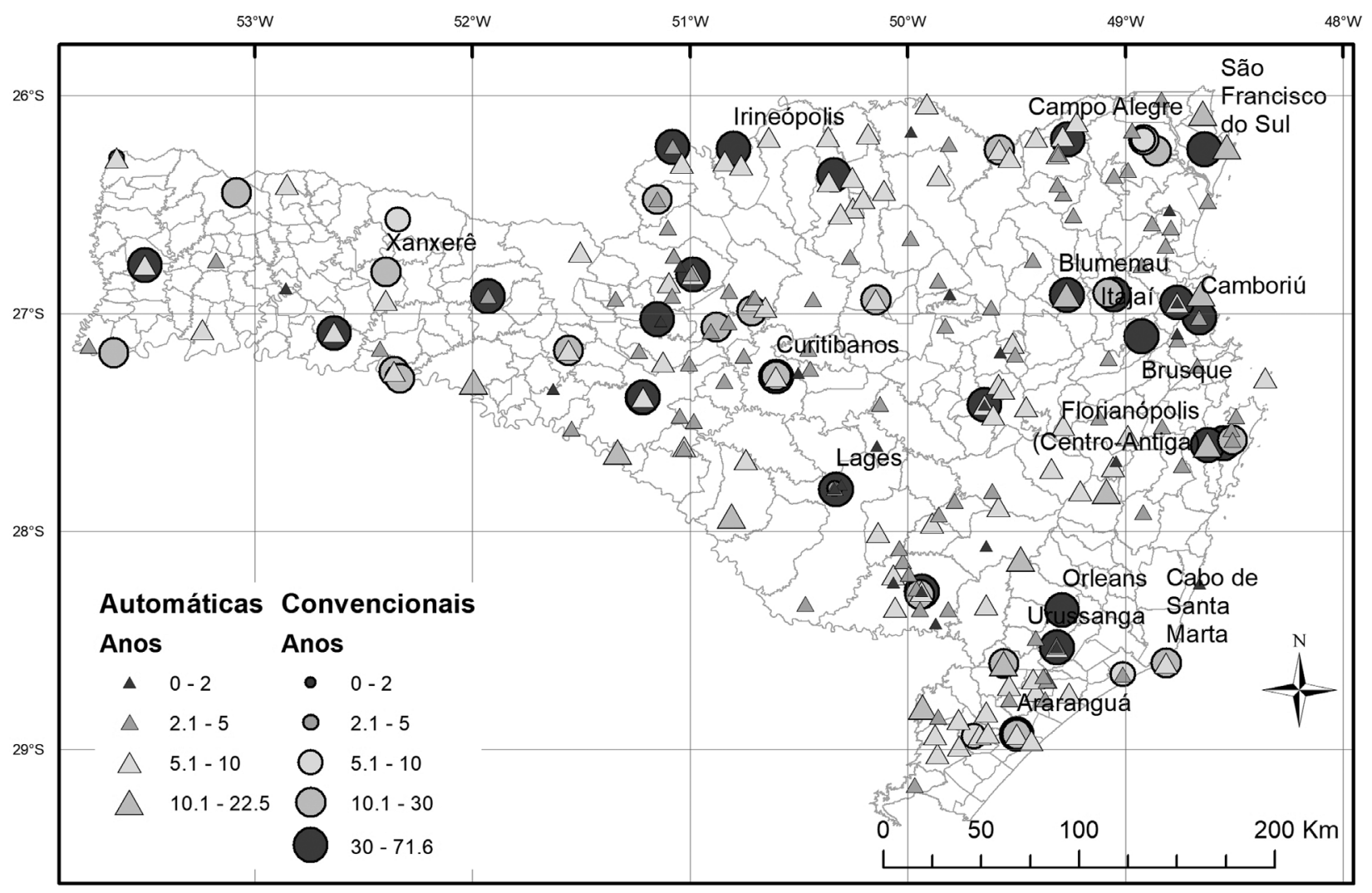

Figura 6 - Distribuição espacial do período de "operação" das estações meteorológicas convencionais e telemétricas ativas e desativadas no estado de Santa Catarina de 1911 a 30/06/2017. 


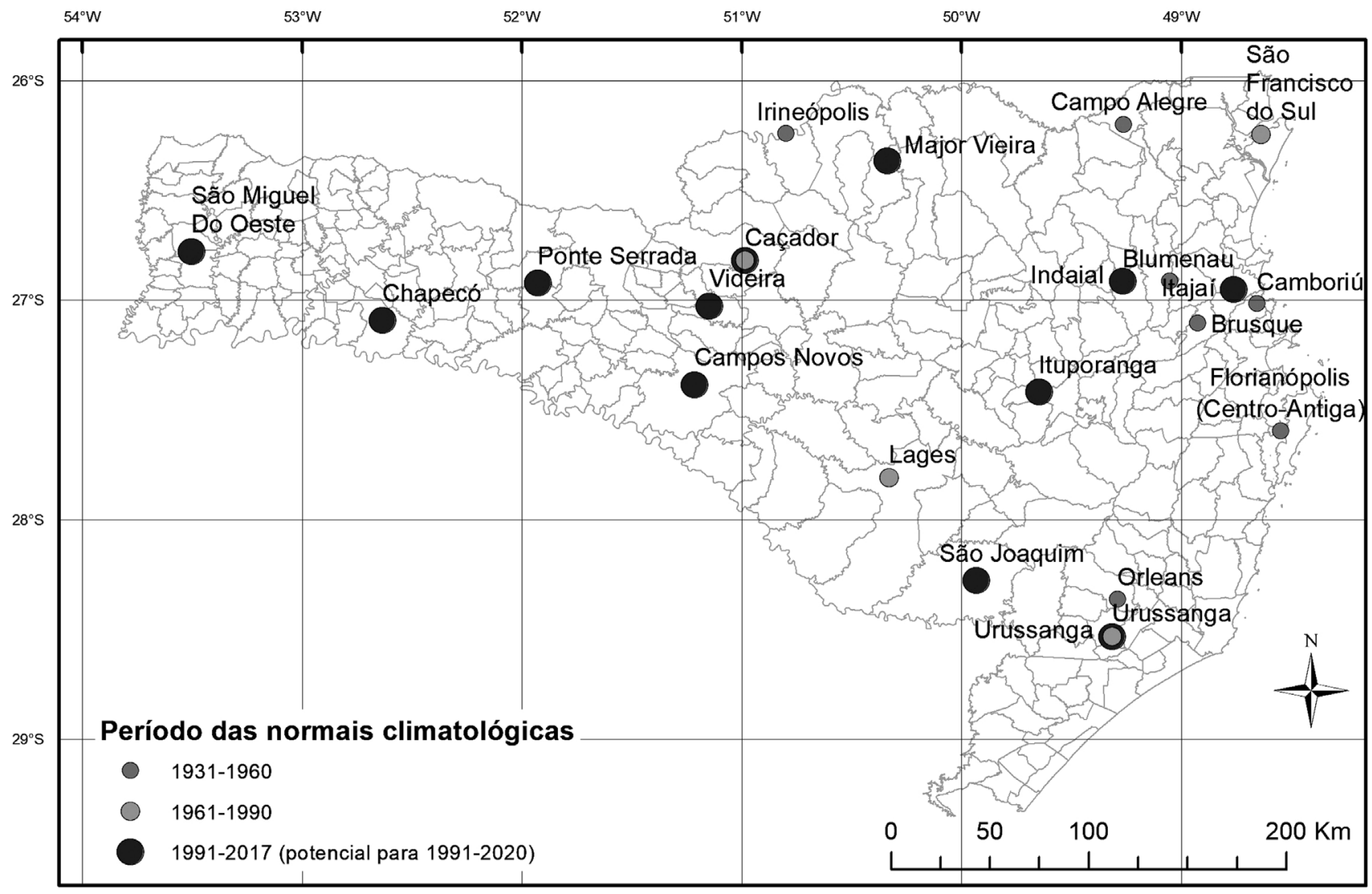

Figura 7 - Distribuição espacial das estações meteorológicas convencionais com períodos de operação coincidentes aos períodos das normais climatológicas padrão da WMO (WMO, 1989).

tradas 7 estações e para o período 1961-1990, 4 estações. A distribuição espacial das estações meteorológicas para os dois primeiros períodos de cálculo das normais climatológicas não cobre integralmente o território de Santa Catarina. Regiões importantes como o Oeste, o Planalto Sul, o Litoral Sul e o Meio Oeste não possuem dados climatológicos suficientes para o cálculo das normais entre 1931 e 1990 .

As estações com dados históricos de 30 anos para os períodos 1931-1960 e 1961-1990 presentes no banco de metadados da Epagri não coincidem com aquelas listadas nas publicações do INMET (INMET, 1979; INMET, 2009). As normais climatológicas do primeiro período foram calculadas, segundo o INMET (1979), com base em 9 estações meteorológicas, enquanto na base de metadados da Epagri só foram identificadas 7 estações meteorológicas para o mesmo período. E apenas as estações de Camboriú (83898), Florianópolis (83897) e Irineópolis (83865 - antiga Valões) coincidiram nas duas bases de metadados. Para o segundo período o INMET (2009) utilizou 15 estações meteorológicas e na base da Epagri foram identificadas apenas 4, sendo que uma das estações (Caçador) não pertence ao INMET. As outras 3 coincidiram com a lista publicada pelo INMET: Lages (83891), São Francisco do Sul (83847) e Urussanga (83923) (INMET, 2009).
A diferença observada entre as estações utilizadas pelo INMET e aquelas identificadas no banco de metadados da Epagri para os dois primeiros períodos de cálculo das normais climatológicas está relacionada à falta de integração entre as bases de metadados meteorológicos existente entre as instituições no Brasil (Vianna et al., 2017). A incerteza gerada pela divergência de códigos, nomes de estações, instituições responsáveis e datas de início e fim de operação entre os cadastros do INMET e da Epagri, colocam em dúvida a garantia da qualidade no uso dos dados gerados por essas estações em estudos climatológicos.

Para o período atual (1991-2020), foram encontradas 11 estações potenciais para o cálculo das normais climatológicas. Essas estações possuem uma distribuição espacial com maior abrangência do território de Santa Catarina, com carência de dados principalmente no Litoral Sul, Litoral Central e Litoral Norte (Fig. 4). Mas segundo informações dos técnicos da Epagri, essas estações já vêm sendo desativadas desde 2016, apesar de não haver registro de data fim nos seus metadados. Caso elas sejam desativadas, o estado de Santa Catarina perderá a oportunidade de gerar os dados necessários para calcular as normais climatológicas com a melhor distribuição espacial da sua história. Seria de extrema importância a manutenção dessas estações até, pelo menos, o fim do ano de 2020. 
Nenhuma estação meteorológica telemétrica foi instalada antes de 1991, portanto seus dados não coincidem com o próximo período de cálculo para as normais climatológicas em Santa Catarina. Segundo os critérios da WMO (1985), as estações meteorológicas telemétricas em Santa Catarina passarão a ter importância no cálculo das normais climatológicas apenas a partir do ano de 2020.

\subsection{Avaliação do erro de posicionamento geográfico entre os pares de coordenadas originais e os pares de coordenadas atualizados das estações meteorológicas convencionais e telemétricas do estado de Santa Catarina}

Em Santa Catarina, 35,7\% das estações meteorológicas apresentaram erro de posicionamento geográfico (Fig. 8, Tabela 3). Erros de posição horizontal foram observados em $22,5 \%$ das estações, erros de posição vertical ocorreram em $4,8 \%$ das estações e $8,4 \%$ das estações apresentaram erros concomitantes de posição horizontal e vertical.

Na Fig. 8, estão representadas as estações meteorológicas com erros de posicionamento horizontal superiores a $110 \mathrm{~m}$ e com erro de posicionamento vertical superior a $30 \mathrm{~m}$.

Não foi identificado nenhum padrão de deslocamento, entre as estações com erros verticais, que pudesse justificar algum tipo de erro sistemático, como por exemplo a troca de sistemas de referência cartográfica. Isso demonstra que as diferenças de posicionamento das estações são de natureza diversificada e não seguem nenhuma tendência espacial. Também foi observado que tanto os erros horizontais quanto os verticais ocorreram por todo o território de Santa Catarina, não havendo nenhum processo de regionalização que indicasse problemas operacionais locais.

As estações telemétricas apresentaram erros de posicionamento horizontal, em média, superiores aos erros encontrados nas estações convencionais (Tabela 4). Essa diferença nos erros horizontais médios observados entre as estações telemétricas e as estações convencionais foi aumentada significativamente pelo erro de posição de 11 estações telemétricas, com códigos 2221, 2230, 1509, 1511, 1514, 1029, 1028, 2019, 1026, 1517 e 1027. Essas estações apresentaram erros horizontais entre 23 e $452 \mathrm{~km}$.

Das 11 estações com erros horizontais superiores a $23 \mathrm{~km}$, apenas a estação 2019 apresentou data de início anterior a 2008. Isso demonstrou que, apesar da existência de um roteiro para cadastro das estações desde 2008, os erros de posicionamento das estações continuam ocorrendo.

Excluindo as 11 estações meteorológicas telemétricas com erro de posição horizontal superior a $23 \mathrm{~km}$, as demais estações meteorológicas apresentaram erros horizontais inferiores a $17 \mathrm{~km}$, com um erro médio de $2,9 \mathrm{~km}$. Os erros médios observados para as estações convencionais foram de 3,2 km e de 2,3 km para as telemétricas, o que ainda está muito acima do padrão da WMO.

Em relação ao erro médio vertical, não houve diferença significativa entre as estações convencionais e as estações telemétricas. Erros superiores a $100 \mathrm{~m}$ ocorreram apenas em 3 estações (códigos 132, 2303 e 1027). Eliminando as estações com erro vertical superior a $100 \mathrm{~m}$, a média do erro foi de $51,5 \mathrm{~m}$, sendo 50,8 para as estações convencionais e 52,2 para as estações telemétricas. Essa diferença de altitude representa, para equações de estimativa de temperatura em função da altitude, uma variação média de $0,34{ }^{\circ} \mathrm{C}$, que é $70 \%$ maior do que a incerteza média relacionada às medições sistemáticas de temperatura global $\left(0,2^{\circ} \mathrm{C}\right)$ (Folland et al., 2001; Brohan et al., 2006).

Os erros de posicionamento horizontal e vertical apresentam uma importante relação quando se trata de posicionamento geográfico de estações meteorológicas. Com o aumento significativo da precisão, da acurácia e da resolução dos modelos digitais de elevação (ex. USGS, 2006; SDS, 2012) é possível obter dados altimétricos em grades de superfícies contínuas. Com isso, a partir da coordenada de uma estação, obtêm-se facilmente a sua altitude. Muitos estudos climatológicos se utilizam de modelos de regressão para estimar valores de variáveis climáticas (ex. temperatura, probabilidade de geada, etc.) a partir das coordenadas geográficas e da altitude das estações (ex. Massignan e Pandolfo, 2006). Esses modelos de regressão são utilizados para gerar superfícies contínuas de variáveis climáticas, usando como base os modelos digitais de elevação (ex. Hijmans et al., 2005). Erros de posicionamento geográfico das estações aumentam as inconsistências nos modelos de regressão e não são detectáveis através de testes estatísticos. Vianna et al. (2017) demonstraram que a variabilidade espacial gerada apenas pela precisão definida pelo formato dos valores das coordenadas, já é suficiente para ocasionar erros significativos no cálculo da temperatura através das equações de regressão.

Tanto as inconsistências referentes aos metadados temporais quanto os erros de posicionamento das estações possuem implicações diretas na qualidade dos dados meteorológicos e são considerados fatores não climáticos das inconsistências em séries históricas (Trewin, 2010). Na década de 90 estudos já indicavam que a alteração da paisagem no entorno dos sítios das estações meteorológicas e a falta de documentação sobre as mudanças de sítios e substituição de sensores, causavam dúvidas a respeito da homogeneidade das séries históricas dos dados climatológicos (Easterling e Peterson, 1995). O mesmo ocorre quando dígitos decimais ou de segundos das coordenadas geográficas são ignorados e/ou arredondados (Vianna et al., 2017). A preocupação científica com a qualidade dos dados e os impactos dos fatores não climáticos sobre essa qualidade ainda persiste (Boissonade et al., 2002; Trewin, 2010; Vianna et al., 2017) e a solução está na adoção de 

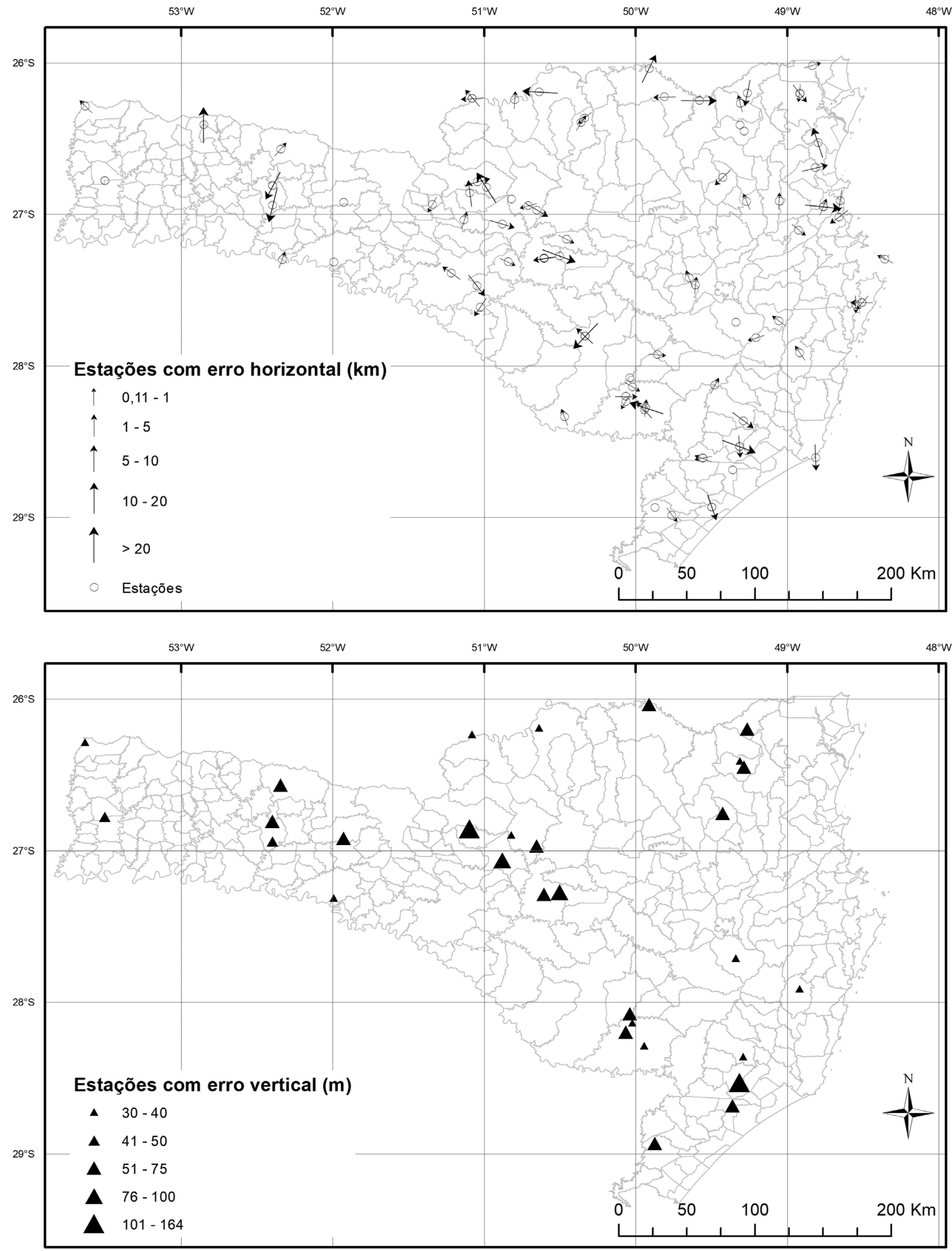

Figura 8 - Distribuição espacial das estações meteorológicas com erro de posicionamento geográfico horizontal e vertical. As estações com erro horizontal superior a 110 m estão simbolizadas por círculos e vetores que representam a variação do erro (em km) e a direção do deslocamento entre as coordenadas originais e as coordenadas corrigidas (setas). As estações com erro vertical superior a $30 \mathrm{~m}$ estão representadas por triângulos. 
Tabela 3 - Número de estações meteorológicas por tipo de problema em Santa Catarina, em 30/06/2017.

\begin{tabular}{l} 
Tipo de problema \\
\hline Sem erro de posicionamento \\
Com erro de posicionamento horizontal (distância euclidiana $\geq 110 \mathrm{~m}$ ) \\
Com erro de posicionamento vertical (diferença absoluta de altitude $30 \geq \mathrm{m})$ \\
Com erro de posicionamento horizontal e vertical (distância $\geq 110 \mathrm{~m}$ e diferença absoluta de altitude $30 \geq \mathrm{m}$ )
\end{tabular}

Tabela 4 - Valores mínimos, médios, máximos e desvio padrão da distância euclidiana e da altitude entre os pares de coordenadas originais e corrigidos para diferentes status e tipo de estação meteorológica do estado de Santa Catarina em 30/06/2017.

\begin{tabular}{|c|c|c|c|c|c|c|c|c|c|}
\hline Status & Tipo & Dist. mín. & Dist. méd. & Dist. máx & Dist. DP. & Alt. mín. & Alt. méd. & Alt. $\max$. & Alt. DP. \\
\hline Ativada & Convencional & 76 & 335 & 1051 & 478 & 16 & 39 & 75 & 27 \\
\hline Ativada & Telemétrica & 16 & 35114 & 452027 & 92465 & 0 & 29 & 164 & 34 \\
\hline Desativada & Convencional & 90 & 3284 & 13650 & 3960 & 0 & 25 & 100 & 26 \\
\hline Desativada & Telemétrica & 46 & 17877 & 270649 & 67418 & 1 & 23 & 72 & 21 \\
\hline
\end{tabular}

padrões internacionais e no cumprimento das normas de boas práticas (WMO, 2002; WMO,2008; WMO, 2015).

\section{Conclusões}

O estado de Santa Catarina possui poucas estações meteorológicas com séries históricas acima do período mínimo de 30 anos, indicado pela WMO para realizar estudos climáticos. Além disso, a distribuição espacial dessas estações não atende ao padrão de representatividade territorial estabelecido pela WMO. A atual rede de estações apresenta uma distribuição espacial com uma cobertura do território quase integral, porém há uma tendência clara de descontinuidade na coleta de dados devido à desativação das estações convencionais e à redução significativa dos períodos de operação das estações telemétricas. Mesmo após um trabalho de ajuste de coordenadas e da elaboração de um roteiro para coleta e cadastro dos metadados espaciais das estações meteorológicas, em 2008, algumas estações mais recentes continuam apresentando problemas de cadastro de coordenadas e altitude. O estado de Santa Catarina vem avançando nos processos de gestão da sua rede de estações, mas precisa se adequar a todas as recomendações da WMO, no que se refere à qualidade dos metadados temporais e espaciais das estações de monitoramento climático.

\section{Referências}

ANA, Agência Nacional de Águas. Orientações para Elaboração do Relatório de Instalação de Estações Hidrométricas. ANA, Brasília, 2014.

ÁVILA, A.; JUSTINO, F.; WILSON, A.; BROMWICH, D.; AMORIM, M. Recent precipitation trends, flash floods and landslides in southern Brazil. Environ. Res. Lett. v. 11, p. 1-13, 2016.

BACK, Á.J.; PASINI, M.L. Analysis of the stochastic model of the Markov chain on daily rainfall occurrence in the state of
Santa Catarina, Brazil. Manag. Environ. Qual. An Int. J. v. 28, p. 2-16. 2017.

BLAINSKI, E.; GARBOSSA, L.H.P.; ANTUNES, E.N. Estações hidrometeorológicas telemétricas: recomendações técnicas para instalação. Florianópolis: Epagri, 43p. 2012. (Epagri. Documentos, 240).

BOISSONNADE, A.C., HEITKEMPER, L.J.; WHITEHEAD, D. Weather data: cleaning and enhancement, in: Climate Risk and the Weather Market. p. 73-93. 2002.

BRAGA, H.J.; RICCE, W. do S.; PANDOLFO, C.; GARBOSA, L.H.P.; MASSIGNAM, A.M.; BLAINSKI, E.; VIEIRA, H.J. Agrometeorologia Catarinense: estações convencionais. Florianópolis: Epagri,. 86p. 2015 (Epagri. Documentos, 250).

BRASIL. Decreto No 89.817, de 20 de Junho de 1984. Estabelece as Instruções Reguladoras das Normas Técnicas da Cartografia Nacional. Subchefia para Assuntos Jurídicos, Casa Civil, Presidência da República. 1984. Disponível em http://www.planalto.gov.br/ccivil_03/decreto/1980-1989/D 89817.htm. Acesso em 27/07/2017.

BROHAN, P.; KENNEDY, J.J.; HARRIS, I.; TETT, S.F.B.; JONES, P.D. Uncertainty estimates in regional and global observed temperature changes: A new data set from 1850. J. Geophys. Res. Atmos. v. 111, p. 1-21. 2006.

DEGE. Atlas Geográfico de Santa Catarina, 2nd ed. Departamento Estadual de Geografia e Cartografia, Santa Catarina. 148p. 1958.

DE MELLO, Y.R.; DE OLIVEIRA, T.M.N. Análise estatística e geoestatística da precipitação média para o município de Joinville (SC). Rev. Bras. Meteorol. v. 31, p. 229-239. 2016.

EASTERLING, D.R.; PETERSON, T.C. A new method for detecting undocumented discontinuities in climatological time series. Int. J. Climatol. v. 15, p. 369-377. 1995.

EMBRAPA. Atlas Climatológico da Região Sul do Brasil. Estados do Paraná, Santa Catarina e Rio Grande do Sul. Empresa Brasileira de Pesquisa Agropecuária - Embrapa. Atlas, 336p. 2011.

ESRI; DIGITALGLOBE; GEOEYE; I-CUBED; USDA; USGS; AEX; GETMAPPING; AEROGRID; IGN; IGP; 
SWISSTOPO; THE GIS USER COMMUNITY. Serviço de imagens em diversas resoluções. 2017. Disponível em https://www.arcgis.com/home/item.html?id 10df2279f9684e4a9f6a7f08febac2a9. Acesso em $17 / 07 / 2017$.

FOLLAND, C.K.; RAYNER, N.A.; BROWN, S.J.; SMITH, T.M.; SHEN, S.S.P.; PARKER, D.E.; MACADAM, I.; JONES, P.D.; JONES, R.N.; NICHOLLS, N.; SEXTON, D.M.H. Global temperature change and its uncertainties since 1861.pdf. Geophys. Res. Lett. v. 28, p. 2621-2624. 2001.

HIJMANS, R.J.; CAMERON, S.E.; PARRA, J.L.; JONES, P.G.; JARVIS, A. Very high-resolution interpolated climate surfaces for global land areas. International Journal of Climatology v. 25, p. 1965-1978. 2005.

INMET, Instituto Nacional de Meteorologia. Normais climatológicas. INMET, Rio de Janeiro. $2^{\mathrm{a}}$ Ed. 1979.

INMET, Instituto Nacional de Meteorologia. Normais climatológicas do Brasil 1961-1990. INMET, Brasília. 465p. 2009 .

INMET, Instituto Nacional de Meteorologia. Rede de estações meteorológicas telemétricas do INMET. Nota Técnica No. 001. INMET, Brasília. 2011.

MASSIGNAM, A. M. e PANDOLFO, C. Estimativa das médias das temperaturas máximas, médias e mínimas do ar decendiais e anuais do Estado de Santa Catarina. Florianópolis: Epagri. Série Documentos n. 224, 2006.

MINISTÉRIO DA AGRICULTURA. Relatório apresentado ao Presidente da República dos Estados Unidos do Brasil pelo Ministro de Estado da Agricultura, Indústria e Comércio. v. I. p. 108-111. 1917. Disponível em: http://brazil.crl.edu/bsd/bsd/u2009/000121.html Acesso em 28/07/2017.

PANDOLFO, C. (Coord.); MASSIGNAM, A. M.; BRAGA, H. J.; SILVA JUNIOR, V. P. da; VIEIRA, V. F.; THOME, V. M R. Atlas Climatológico do Estado de Santa Catarina. Florianopolis: Epagri, 2002. CD-ROM.

PBMC. Mudanças Climáticas e Cidades. Relatório Especial do Painel Brasileiro de Mudanças Climáticas, Ribeiro, S.K.; Santos, A.S. (eds), PBMC, COPPE, Rio de Janeiro, 116 p. 2016.

Santa Catarina. Política Estadual sobre Mudanças Climáticas e Desenvolvimento Sustentável de Santa Catarina. Florianópolis. 2009.
SDS - Secretaria de Estado do Desenvolvimento Sustentável de Santa Catarina. Relatório final de produção do aerolevantamento e modelo digital de terreno de Santa Catarina. Florianópolis, 218 p. 2012.

SIEBERT, C. Mudanças Climáticas e Desastres Naturais em Santa Catarina: Impactos Socioterritoriais e Avaliação das Políticas Públicas, in: XVII Encontro Nacional da Associação Nacional de Pós-Graduação e Pesquisa em Planejamento Urbano e Regional. São Paulo, p. 1-22. 2017.

TREWIN, B. Exposure, instrumentation, and observing practice effects on land temperature measurements. Wiley Interdiscip. Rev. Clim. Chang. v. 1, p. 490-506. 2010.

USGS. Shuttle Radar Topography Mission. 3 Arc Second, Filled Finished 2.0, Global Land Cover Facility. Jet Propulsion Laboratory, California: California Institute of Technology. February 2000. 2006.

VIANNA, L.F.; PERIN, E.B.; RICCE, W. DA S.; MASSIGNAM, A.M.; PANDOLFO, C. Bancos de Dados Meteorológicos: Análise dos Metadados das Estações Meteorológicas no Estado de Santa Catarina, Brasil. Rev. Bras. Meteorol. v. 32, p. 53-64. 2017.

WMO - World Meteorological Organization. Calculation of monthly and annual 30-year standard normals. WCDP 10 and WMOTD 341, in: Meeting of Experts. WMO WORLD METEOROLOGICAL ORGANIZATION, Washington, D.C., p. 14., 1989.

WMO - World Meteorological Organization. Guide to the Global Observing System, WMO n ${ }^{\circ}$ 488, $3^{\mathrm{a}}$ ed., Genebra, Suíça, 2007.

WMO - World Meteorological Organization. Guidelines for Managing Changes in Climate

Observation Programmes, WMO-TD No. 1378., Genebra, Suíça, $2007 \mathrm{~b}$.

WMO- World Meteorological Organization. Guide to Meteorological Instruments and Methods of Observation,WMO n. 8. Genebra, Suíça, 2008.

WMO - World Meteorological Organization. WIGOS Metadata Standard. WMO Thecnical Regulations (WMO-NO. 49) Manual on WIGOS. World Meteorological Congress. Geneva, 117p. 2015.

WREGE, M.S.; HERTER, F.G.; FRITZSONS, E. Regiões Com Similaridade De Horas De Frio No Outonoinverno No Sul Do Brasil. Rev. Bras. Climatol. v. 18, p. 99-111. 2016.

This is an Open Access article distributed under the terms of the Creative Commons Attribution Non-Commercial License which permits unrestricted non-commercial use, distribution, and reproduction in any medium provided the original work is properly cited. 